\title{
Lag Analysis of Vegetation NDVI and Precipitation in Liaoning Province
}

\author{
Xinyu Bi, Xiaojing Liu* \\ College of Tourism and Geographic Science, Jilin Normal University \\ Siping 136000, China
}

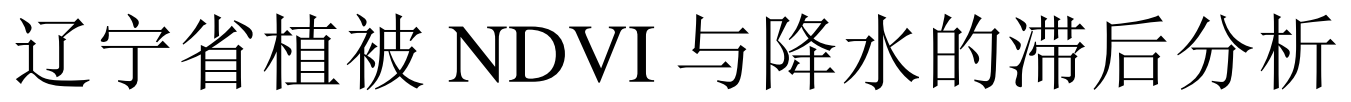

\author{
毕馨予, 刘晓静* \\ 吉林师范大学旅游与地理科学学院 \\ 四平 136000 , 中国
}

\begin{abstract}
Vegetation growth is a complex and slow process. Not only was it affected by the precipitation at that time, but also the accumulation of precipitation in the early stage played a certain role in its growth. That is, vegetation growth lags behind precipitation. Based on SPOT/VEGETATION ten-day NDVI data and meteorological station data from 1998 to 2013. The dynamic changes of NDVI of vegetation in Liaoning Province and the lagging relationship between NDVI and precipitation were analyzed when the effect of temperature on vegetation was removed. Revealing the influence of temperature on the lag relationship between NDVI and precipitation. The results show : (1) The overall trend of NDVI change in each site is remarkably consistent and the dynamic change law is obvious. (2) When the temperature effect is eliminated and the temperature effect is not eliminated. In May and June, the lagging days of vegetation on precipitation remained unchanged, all of which were 90 days. The number of days lagging in July, August and September has changed, July was 60 days and 70 days, August was 10 days and 90 days, September was 20 days and 90 days. It shows that temperature has an effect on the lag of vegetation on precipitation. The results can provide theoretical basis for regional drought prediction.
\end{abstract}

Keywords-NDVI; precipitation; temperature; hysteresis Analysis

摘要一植被生长是一个复杂且缓慢的过程，不仅受当时降 水的影响, 前期降水的积累对其生长也有一定的作用, 即植 被生长对降水有滞后性。本文基于 1998-2013 年 SPOT/VEGETATION 逐旬 NDVI 数据和气象站点的数据, 分 析辽宁省植被 NDVI 动态变化以及在剔除温度对植被影响的 情况下 NDVI 与降水的滞后关系, 并与未剔除温度影响的 NDVI 与降水的滞后关系进行对比, 探讨不同月份植被对降水 的滞后天数, 揭示温度对 NDVI 与降水的滞后关系的影响。 结果表明: (1)各站点 NDVI 整体变化趋势呈显著的一致性且 动态变化规律明显。(1)剔除温度影响和未剔除温度影响下, $5 、 6$ 月植被对降水的滞后天数没有变化, 都为 90 天。 $7 、 8 、$ 9 月的滞后天数发生了变化, 7 月分别为 60 天和 70 天, 8 月 分别为 10 天和 90 天, 9 月分别为 20 天和 90 天, 表明温度在 研究植被对降水的滞后性上是有影响的。研究结果可为区域 干旱预测提供理论依据。

关键词: NDVI; 降水; 温度; 滞后分析

\section{I. 引言}

全球气候变化及其对生态系统的影响已经成为研究 的重点。植被作为陆地生态系统重要的组成部分, 对维 持生态系统稳定性起着至关重要的作用。植被对气候变 化的响应能够很好地表征陆地生态系统的变化及发展, 其中气温和降水的变化对植被生长的影响最为明显 [15]。

植被在生长过程中受外界因子影响对气候因子存在 滞后反应。卫星遥感技术能够获取大范围的、长时间序 列的影像数据, 为作物长势监测、产量估算、农业灾害 监测提供重要的数据来源[6]。由卫星遥感技术获得的归 一化植被指数 (NDVI) 是监测植被长势和衡量植被覆 盖度的最佳指示因子, 已经成为研究植被对气候因子响 应的重要手段与方法[7-9]。目前关于植被对降水的滞后 研究很多 [10-12]。植被的生长受温度和降水的共同影 响, 但目前大多研究在进行 NDVI 与降水的滞后分析 时, 没有剔除温度对植被的影响。因此, 本文以辽宁省 为研究区, 在剔除温度的影响下, 对 NDVI 与降水进行 滞后分析, 为区域植被长势监测、干旱预测、应对气候 变化提供参考。

\section{II. 材料与方法}

\section{A. 研究区概况}

辽宁省位于中国东北部, 地理位置为 $118^{\circ} 53^{\prime} \mathrm{E} \sim 125^{\circ} 46^{\prime} \mathrm{E}, 38^{\circ} 43^{\prime} \mathrm{N} \sim 43^{\circ} 26^{\prime} \mathrm{N}$ 。辽宁省东部和西 部为平均海拔 800 米和 500 米的山地丘陵, 中部为平均 海拔 200 米的辽河平原，地势大致为自东西两侧向中部 倾斜。全年平均气温在 $7-11^{\circ} \mathrm{C}$ 之间, 最高气温达 $30^{\circ} \mathrm{C}$, 最低气温零下 $30^{\circ} \mathrm{C}$, 年均温度从西南向东北方向 逐渐降低。年降水量在 600-1100mm 之间，但各地降 雨分布不均，总体年降水量从东南向西北方向呈逐渐降 低的趋势。

\section{B. 数据来源与处理}

采用 1998-2013 年 SPOT/VEGETATION 的 VGT-S10 逐旬 NDVI 数据。考虑到数据的连续性和有效性, 在研

基金项目：吉林师范大学研究生科研创新计划资助项目（研创新 201945）

作者简介：毕馨予（1996-），女，硕士研究生。研究方向：自然灾害监测、风险评估与管理。Email: Bxyu27@163.com *通讯作者：刘晓静（1985-），女，博士，主要从事自然灾害风险评价与管理方面的教学和科研工作。Email: liuxj@jlnu.edu.cn 
究区内选择了分布均匀且连续的 24 个站点（如图 1）。 植被生长对气候因子的变化具有滞后性, 而且这种滞后 作用在植被生长的不同阶段也是不相同的[13]。由于 4 月初植被很少, 植被覆盖度较低, 受气候影响波动较 小，因此将植被生长季分为 5 月、 6 月、 7 月、 8 月、 9 月五个时间段，采用最大值合成法，获得研究区 5-9 月 的 NDVI 影像。研究表明, 一般取气象站点的有效数据 的范围为 $12 \mathrm{~km}$ [14.15]。因此以气象站点为中心，以 $3 \mathrm{~km}$ 为半径做圆形缓冲区, 以缓冲区内 NDVI 的平均值作为 该气象站点植被的 NDVI 值。

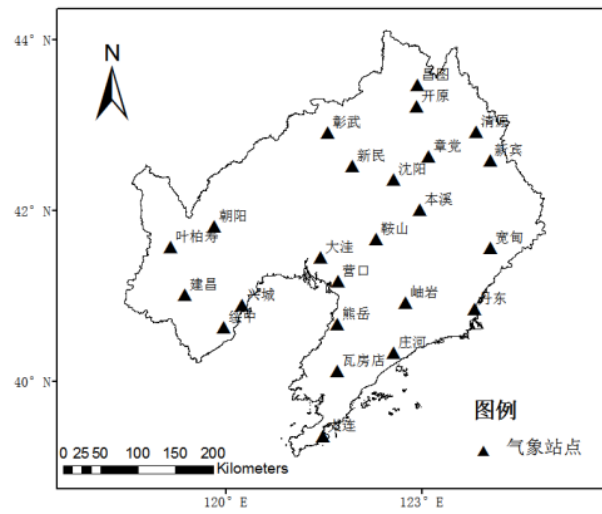

图 1 研究区及气象站点分布

Figure 1 Distribution of research area and meteorological

station

气象数据来源于中国气象数据网 (http://data.cma.cn/) 中的 1998-2013 年的逐日气温、降 水资料。由于研究所采用的遥感数据是以旬为尺度, 因 此气温、降水资料也以旬为最小时间尺度进行累加。

\section{C. 植被 NDVI 与降水的滞后分析}

植被在生长过程中受温度和降水的共同作用，因此二 者同时与表征植被生长状态的 NDVI 相关，这种相关关 系中夹杂了彼此之间的相互影响。为了更真实地反映
NDVI 与降水之间的滞后关系, 在进行 NDVI 与降水的 滞后分析时, 剔除温度的影响, 进而更准确地表达植被 对降水的滞后反应。

\section{III. 结果与分析}

\section{A. 植被 NDVI 年内与年际变化规律}

图 2 为研究区各站点植被 1998-2013 年 4-9 月旬 NDVI 平均值的变化图。由图 2 可知, 各站点植被 NDVI 曲线在生长阶段都大致呈单峰型。NDVI 值在 4 月初最 小, NDVI 曲线呈逐渐增加的趋势。NDVI 最大值出现在 8 月到 9 月间, 这段时间是植被生长最茂盛的阶段。9 月 初植被逐渐进入枯黄期, NDVI 值下降。各个站点 NDVI 的大小虽然不同，但整体变化趋势呈显著的一致性。

图 3 为 1998-2013 年各站点 NDVI 值年际变化图。 各站点的 NDVI 值为当年所有时间序列 NDVI 的平均 值。除了清原和新宾的年际 NDVI 值最大、营口的年际 NDVI 值最小之外，其他站点 NDVI 值都集中在 0.3-0.5 之间。总体来看 1998-2013 年间 NDVI 值变化不大, 植 被生长活动变化不显著。

\section{B. NDVI 与降水的滞后分析}

剔除温度影响之后 NDVI 与降水的相关系数变化趋势 如图 4a 所示。由图 4a 可知, 5 月 NDVI 与累积 20 天降 水的相关系数最小, 之后逐渐增加, 与累积 90 天降水的 相关系数最大, 整体变化呈逐渐增加的趋势。6 月 NDVI 与累积 50 天降水的相关系数最小, 与累积 90 天降水的 相关系数最大, 变化趋势为先增加后减少再增加。7 月 NDVI 与累积 10 天降水的相关系数最小, 与累积 60 天 降水的相关系数最大, 整体变化趋势为先增加后减少。

8 月 NDVI 与累积 10 天降水的相关系数最大, 与累积 40 天降水的相关系数最小, 整体变化趋势为先减少后增 加。9 月 NDVI 与累积 20 天降水的相关系数最大, 与累 积 90 天降水的相关系数最小, 整体变化呈逐渐减少的趋 势。5、6、7、8、9 月植被对降水的滞后天数分别为 90、90、60、10、20 天。

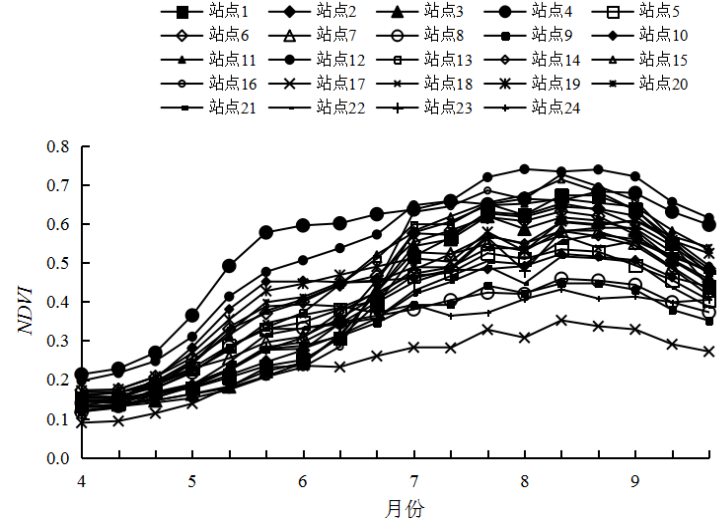

图 2 各站点 NDVI 年内动态变化

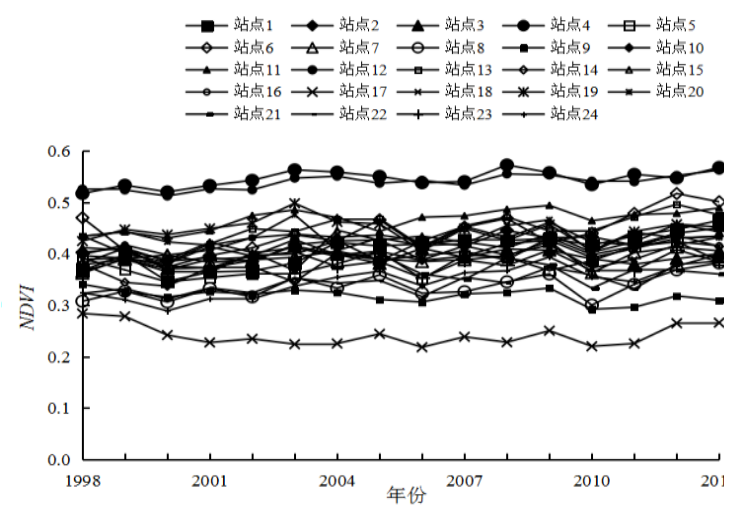

图 3 各站点 NDVI 年际动态变化

Figure 2 Dynamic changes of NDVI in each site during the year Figure 3 Interannual Dynamic Change of NDVI at Each Site 

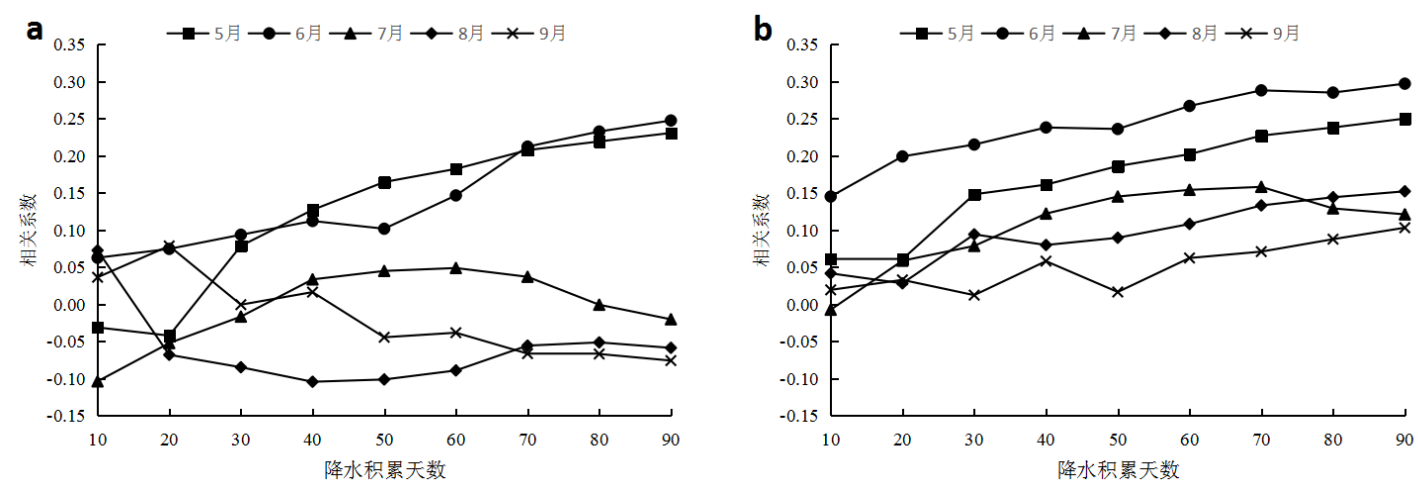

图 4 NDVI 与降水的相关系数变化图（a: 剔除温度影响 $\mathrm{b}$ : 未剔除温度影响）

Figure 4 Change of correlation coefficient between NDVI and precipitation (a: Eliminate temperature effects b: Temperature effects not excluded)

\section{C. 对比分析}

未剔除温度影响的 NDVI 与降水的相关系数变化趋 势如图 $4 \mathrm{~b}$ 所示。由图 $4 \mathrm{~b}$ 可知, 5 月 NDVI 与累积 20 天 降水的相关系数最小, 与累积 90 天降水的相关系数最 大，相关系数变化呈逐渐增加的趋势。6 月相关系数整 体变化趋势与 5 月相同, NDVI 与累积 10 天降水的相关 系数最小, 与累积 90 天降水的相关系数最大。 7 月 NDVI 与累积 70 天降水的相关系数最大, 与累积 10 天 降水的相关系数最小, 整体变化趋势为先增加后减少。

8 月 NDVI 与累积 90 天降水的相关系数最大, 与累积 20 天降水的相关系数最小, 变化趋势为先减少后增加, 再 减少后增加。9 月相关系数整体变化呈逐渐增加的趋 势, NDVI 与累积 90 天降水的相关系数最大, 与累积 30 天降水的相关系数最小。5、6、7、8、9 月植被对降 水的滞后天数分别为 $90 、 90 、 70 、 90 、 90$ 天。

通过对比剔除温度影响和未剔除温度影响情况下的 NDVI 与降水的相关系数变化趋势可以得出: 5 月和 6 月 相关系数的变化趋势相同, 都是 NDVI 与累积 90 天的 相关系数最大，滞后天数为 90 天，说明在 5、6 月植被 生长主要受降水的影响。7 月相关系数的变化都呈先增 加后减少的趋势, 但最大相关系数所对应的累积天数分 别为 60 天 (剔除温度影响) 和 70 天 (未剔除温度影 响）, 相应滞后天数分别为 60 天和 70 天, 表明在 7 月 温度对植被的滞后性有一定的影响。8 月相关系数的变 化趋势差异明显, 最大相关系数对应的累积天数分别为 10 天 (剔除温度影响) 和 90 天 (未剔除温度影响), 相应滞后天数分别为 10 和 90 天, 差异较大, 表明 8 月 温度对植被的滞后性影响较大。9 月相关系数的变化趋 势差异很大, 最大相关系数对应的累积天数分别为 20 天 (剔除温度影响) 和 90 天 (未剔除温度影响), 相 应滞后天数分别为 20 天和 90 天，表明 9 月温度对植被 的滞后性影响也较大。 $8 、 9$ 月植被的滞后天数相差较 多, 表明植被在 8 月和 9 月的生长状态对降水的滞后性 受温度的影响较大。

\section{IV. 结论与讨论}

NDVI 能够很好地表征植被的生长状态, 在剔除温度 影响之后对植被 NDVI 与降水的关系进行研究, 可以更 好地探讨植被对降水的滞后性, 本文主要研究结果如 下:
(1) 研究区内植被 NDVI 变化都呈单峰型。4 月初 NDVI 值最小, 5-7 月植被生长较快, NDVI一般在 8 月 上旬达到最大。各站点年际 NDVI 变化不大, 近 16 年 植被生长活动变化不显著。

（2）剔除温度影响与未剔除温度影响各月植被对降 水的滞后天数变化情况: 5、6 月没有变化, 滞后天数都 为 90 天。 $7 、 8 、 9$ 月有变化, 7 月分别为 60 天和 70 天，8 月分别为 10 天和 90 天，9月分别为 20 天和 90 天。滞后天数发生变化, 表明温度在研究植被对降水的 滞后性上是有影响的。

但是植被在实际生长过程中对降水的滞后性一定会 受到温度的影响, 本文剔除温度影响探讨植被对降水的 滞后反应，目的是通过这种滞后反应分析植被对降水的 敏感性, 从而更好地对植被的脆弱性进行研究。

\section{参考文献}

[1] WANG J, RICH P M and PRICE K P, "Temporal responses of NDVI to precipitation and temperature in the central Great Plains ,USA, " J. International Journal of Remote Sensing, vol. 24, issue 11, pp. 2345 $-2364,2003$.

[2] Wang J,Price KP and Rich PM, "Spatial patterns of NDVI in response to precipitation and temperature in the central Great Plains," J. International Journal of Remote Sensing, vol. 22, issue 18, pp. 3827-3844, 2001

[3] Yu F, Price KP, Ellis J, Shi PJ, "Response of seasonal vegetation development to climatic variations in eastern central Asia," J. Remote Sensing of Environment, vol. 87, issue 1, pp. 42-54, 2003.

[4] 张景华,封志明,姜鲁光,等. “澜沧江流域植被 NDVI 与气候因子的 相关性分析,”自然资源学报, vol .30, issue 9, pp. 1425-1435, 2015.

[5] Xiaojing Liu, Donglai Ma, Jiquan Zhang, Peng Chen. , "The Study of Estimation on Maize Irrigation Water Requirement in the northwest of Liaoning Province," J. Journal of Risk Analysis and Crisis Response, vol. 9-1, pp. 52-59, 2019.

[6] 马明国,王建,王雪梅, “基于遥感的植被年际变化及其与气候关系 研究进展,”遥感学报, issue 3, pp. 421-431, 2006 .

[7] 方修琦,余卫红, “物候对全球变暖响应的研究综述,”地球科学进 展, issue 5, pp. 714-719, 2002.

[8] Tucker CJ, Slayback DA ,Pinzon JE, Los SO,Myneni RB,Taylor MG, "Higher northern latitude normalized difference vegetation index and growing season trends from 1982 to 1999 ," J. International Journal of Biometeorology, vol. 45, issue 4, 2001.

[9] 曹永强,张亮亮,袁立婷, “辽宁省植被生长季 NDVI 对气候因子的 响应,”植物学报, vol. 53, issue 1, pp. 82-93, 2018. 
[10] 洪欣, 唐晓玲, 李宝庆, 等. “吉林省西部草地 NDVI 变化特征及与气 温降水相关性分析, ”气象灾害防御, vol. 24, issue 1, pp. 45-48, 2017.

[11] 刘成林,樊任华,武建军,等. “锡林郭勒草原植被生长对降水响应的 滞后性研究,”干旱区地理, vol. 32, issue 4, pp. 512-518, 2009.

[12] 崔林丽,史军, “中国华东及其周边地区 NDVI 对气温和降水的季 节响应,”资源科学, vol. 34, issue 1, pp. 81-90, 2012.

[13] 朴世龙,方精云, “1982-1999 年我国陆地植被活动对气候变化响应 的季节差异,”地理学报, issue 1, pp. 119-125, 2003.
[14] 朴世龙,方精云, “1982-1999 年我国陆地植被活动对气候变化响应 的季节差异,”地理学报, issue 1, pp. 119-125, 2003.

[15] 罗玲,王宗明,宋开山,等. “1982 2003 年中国东北地区不同类型植 被 NDVI 与气候因子的关系研究, ”西北植物学报, vol. 29, issue 4, pp. 800-808, 2009.

[16] 王宏,李晓兵,龙慧灵,等. “整合 1982-1999 年 NDVI 与降雨量时 间序列模拟中国北方温带草原植被盖度, ”应用基础与工程科学学 报, issue 4, pp. 525-536, 2008. 